\title{
Circulating Corticosterone in the Infant Rat: The Mechanism of Age and Thyroxine Effects
}

\author{
SUSAN J. HENNING, LUCY L. LEEPER, AND DE N. DIEU \\ Department of Biology, University of Houston, Houston, Texas 77004
}

\begin{abstract}
Infant rats exhibit a marked rise in serum concentrations of corticosterone between postnatal days 12 and 24 . As this rise appears to be cued by $L$-thyroxine, the aim of the current study was to determine the physiological bases of the effects of both age and thyroid status on serum corticosterone. The in vivo response to either adrenocorticotropic hormone $(60 \mathrm{mU} / \mathrm{g}$ body weight) or dibutyryl $3^{\prime}, 5^{\prime}$-cyclic adenylate $(0.3 \mathrm{mg} / \mathrm{g}$ body weight) increased between 10 and 16 days and was advanced and delayed by hyper- and hypothyroidism, respectively. In contrast, in vitro studies with adrenals from rats aged 10 and 16 days showed no effect of age on either basal or adrenocorticotropic hormone-stimulated production of corticosterone. Chronic administration of exogenous corticosterone to hyperthyroid animals resulted in significantly higher concentrations of serum corticosterone than did an identical administration to hypothyroid animals. As hyperthyroidism was associated with marked elevations in the concentration of corticosteroid-binding globulin and in the extent of binding of corticosterone, these results suggest that the effects of both age and thyroid status on serum concentrations of corticosterone may reflect changes in the metabolic clearance of the hormone. (Pediatr Res 20: 87-92, 1986)
\end{abstract}

\section{Abbreviations}

ACTH, adrenocorticotropic hormone

cAMP, 3', 5' -cyclic adenylate

BSA, bovine serum albumin

BW, body weight

CBG, corticosteroid-binding globulin

PTU, $\boldsymbol{n}$-propylthiouracil

$\mathrm{T}_{4}$, L-thyroxine

ip, intraperitoneal

MCR, metabolic clearance rate

In the neonatal rat, circulating concentrations of corticosterone are extremely low on days 6 through 12 , then they rise markedly beginning on day 14 and reaching a peak on days 24-25 (1-3). During this same period the circulating concentrations of ACTH do not change significantly (4). Thus, either the ontogenic increase of corticosterone is independent of ACTH or the system becomes increasingly responsive to the basal concentration of ACTH. There is conflicting evidence regarding the latter possibility (4-6) and the data are difficult to interpret because of the use of a fluorometric method for measuring corticosterone which is now recognized to be inappropriate in young rodents $(1,2,7)$.

Received May 1 1985; accepted August 27, 1985.

Correspondence to Dr. S. J. Henning, Department of Biology, University of Houston, Houston, TX 77004.

This work was supported by grant number R01-HD14094 from the National Institutes of Health.
Therefore, the first aim of the current investigation was to determine the effects of age on the in vivo response of serum corticosterone to ACTH. The second aim was to determine whether these effects could be reproduced using adrenal tissue in vitro.

It has been demonstrated that the $\mathrm{T}_{4}$ status of the rat dramatically influences the ontogeny of serum corticosterone. Daily injection of $\mathrm{T}_{4}$ results in precocious appearance of the corticosterone surge (8-11) while hypothyroidism suppresses the developmental rise of corticosterone $(8,12)$. Thyroxine elevates circulating corticosterone concentrations only in the presence of the hypophysis (12), suggesting that the effect of hyper- and hypothyroidism is mediated either through changes in the output of ACTH by the hypophysis or through changes in the serum corticosterone response to ACTH. Since the circulating concentrations of ACTH apparently do not increase following the normal developmental rise of $\mathrm{T}_{4}(4)$, the third aim of the present study was to determine whether thyroid status affects the in vivo response of serum corticosterone to ACTH. The final aim was to determine whether the effects of thyroid status reflect events at the level of the adrenal or elsewhere.

\section{MATERIALS AND METHODS}

Chemicals. Porcine ACTH (grade II), synthetic ACTH (1-24), dibutyryl cAMP, PTU, L-T 4 , BSA, cholesterol, and nonlabeled corticosterone were obtained from Sigma Chemical Co. (St. Louis, MO). $\left[1,2,6,7-{ }^{3} \mathrm{H}\right]$ corticosterone was obtained from New England Nuclear Corp. (Boston, MA).

Animals. Pregnant rats of the Sprague-Dawley strain [Charles River Crl:CD(SD)BR] were obtained from Charles River Laboratories, Inc., Wilmington, MA. They were received on day 15 of gestation and gave birth in our own animal quarters. On the due date the cages were checked every $2 \mathrm{~h}$ for the presence of pups. The date of birth was designated as day 0 . At approximately $24 \mathrm{~h}$ postpartum the experimental litters were reduced to eight or nine pups. The animals were raised in air-conditioned quarters at $21 \pm 1^{\circ} \mathrm{C}$ on a 12-h light/12-h dark cycle with lights on at 0530 h. Food (Rodent Laboratory Chow 5001; Ralston Purina Co., St. Louis, MO) and deionized water were available ad libitum. All animals were killed between 1100 and $1200 \mathrm{~h}$.

Study 1. A dose response study in 2 litters aged 15 days using doses of $7.5,15,30$, and $60 \mathrm{mU}$ porcine ACTH per $\mathrm{g} \mathrm{BW}$ injected ip showed that the serum corticosterone response plateaued between 30 and $60 \mathrm{mU} \mathrm{ACTH} / \mathrm{g} \mathrm{BW}$ (data not shown). Three litters of nine rat pups were then used to study the effect of age on maximal responsiveness to ACTH administration. On postnatal days 10,13 , and 16 , one pup from each litter was killed immediately (uninjected) to obtain basal values for serum corticosterone; one pup was injected ip with ACTH $(60 \mathrm{mU} / \mathrm{g} \mathrm{BW})$ in $0.15 \mathrm{M}$ citrate-phosphate buffer, $\mathrm{pH} 6.9$; and one pup was injected ip with $0.15 \mathrm{M}$ citrate-phosphate buffer, $\mathrm{pH} 6.9$ (vehicle). Pups receiving either ACTH or vehicle were killed $25 \mathrm{~min}$ postinjection for assay of serum corticosterone. 
Study 2. Hypothyroidism was induced in three litters of rat pups by giving pregnant females PTU $(0.01 \%)$ in their drinking water beginning on day 18 of gestation and continuing for the duration of the experiment. This treatment has been shown to produce physiological hypothyroidism in the progeny (8). From postnatal day 7 onward, each litter was treated as follows: three pups remained hypothyroid (receiving daily vehicle injections); three control pups received a replacement dose of $T_{4}(0.05 \mu \mathrm{g} / \mathrm{g}$ $\mathrm{BW} /$ day); and three pups were made hyperthyroid (receiving $\mathrm{T}_{4}$ at a dosage of $1.0 \mu \mathrm{g} / \mathrm{g} \mathrm{BW} / \mathrm{day}$ ). The replacement dosage has previously been shown to approximately normalize serum concentrations of thyroxine in PTU-treated pups (13). On postnatal days 10,13 , and 16 , one pup from each of the three treatment groups in each litter was injected ip with porcine ACTH (60 $\mathrm{mU} / \mathrm{g} \mathrm{BW}$ ) and then killed 32 min later.

Study 3. Three litters of nine pups were used to study the effect of age on responsiveness to dibutyryl cAMP. Each litter comprised three hypothyroid pups, 3 control pups, and three hyperthyroid pups using the protocol described in study 2 except that hyperthyroidism was induced by administration of a $T_{4}$ dose of $0.5 \mu \mathrm{g} / \mathrm{g} \mathrm{BW} /$ day. On postnatal days 10,13 , and 16 , one pup from each of the three treatment groups in each litter was injected subcutaneously with dibutyryl cAMP $(0.3 \mathrm{mg} / \mathrm{g} \mathrm{BW})$ in $0.9 \%$ $\mathrm{NaCl}$ and then killed 32 min later. Preliminary studies showed that this dosage of dibutyryl cAMP was saturating with respect to the elicited increase of serum corticosterone.

Study 4. Eight litters of nine pups were used to study the in vitro production of corticosterone by adrenal tissue incubated in Krebs-Ringer bicarbonate medium. Animals were sacrificed within $40 \mathrm{~s}$ of disturbing the cage (to ensure basal conditions of corticosterone production). Adrenals were immediately removed to ice-cold saline. After decapsulating, each adrenal was halved. One half was used for incubation in basal (control) medium and the other half was used for incubation in basal medium plus synthetic ACTH (1-24) at a concentration of $250 \mathrm{mU} / \mathrm{ml}$. For rats aged 9-10 days, five to six pups from each litter were required to give sufficient tissue for one control and one ACTH incubation. The remaining three to four pups from each litter were used at 15-16 days of age. Thus, at each age we performed eight paired incubations the presence and absence of ACTH, each pair of incubations representing adrenal tissue from three to six pups from a given litter.

The basal incubation medium was Krebs-Ringer bicarbonate containing BSA $(0.5 \%)$ and glucose $(0.2 \%)$. Incubation was performed under an atmosphere of $95 \% \mathrm{O}_{2}, 5 \% \mathrm{CO}_{2}$, and at a shaking rate of approximately 140 cycles $/ \mathrm{min}$. Each tissue sample was subjected to a $1-\mathrm{h}$ preincubation in $1.0 \mathrm{ml}$ basal medium. After replacement with a further $1.0 \mathrm{ml}$ of either basal medium or basal medium plus ACTH $(250 \mathrm{mU} / \mathrm{ml})$, incubations were continued for another $45 \mathrm{~min}$. These incubation conditions have been successfully employed in studies of in vitro production of corticosterone by adrenal quarters from adult rats (14-16). At the end of the incubation, the medium was removed for assay of corticosterone and the tissue was blotted and weighed. Individual incubations typically contained 3-7 mg of tissue. Results were expressed as $\mu \mathrm{g}$ corticosterone released/100 mg tissue/45 min.

A further four litters were used to study in vitro production of corticosterone by 10- and 16-day adrenals incubated in homologous serum. The methods were exactly as described above except that basal medium was substituted by serum from animals aged 10 and 16 days, respectively.

Study 5. Three litters of eight pups were used to study the effect of thyroid status on serum concentrations of corticosterone following chronic administration of exogenous corticosterone. In each litter, two pups were made hypothyroid and two pups were made hyperthyroid using the protocol described in study 2 except that PTU treatment was initiated 1 day after birth. The remaining four pups in each litter were not used for this experiment. Both the hypo- and hyperthyroid pups were subcutaneously implanted on day 13 with a 9 - to $13-\mathrm{mg}$ pellet consisting of $50 \%$ corticos- terone and $50 \%$ cholesterol according to the method of Meyer et al. (17). All pups were sacrificed at day 16 for collection of serum. In each litter, serum from the two pups in each of the hypo- and hyperthyroid groups was combined to give a pool large enough for determination of total corticosterone, $\mathrm{CBG}$, and percentage bound corticosterone. Results are given as means \pm SE for the pooled sera from the three litters. Thus, although for statistical purposes $n=3$, mean values are representative of a total of six animals.

Total corticosterone in serum was determined using the method described below. The concentration of CBG was determined by measuring the maximal binding capacity of serum $(\mu \mathrm{g}$ corticosterone bound per $\mathrm{dl}$ serum) as described elsewhere $(1,8)$. In addition, the percentage of circulating corticosterone which was protein bound was determined by the tracer technique of Martin et al. (18). Total corticosterone and CBG determinations were performed on frozen serum, whereas percentage bound was performed on fresh serum.

Corticosterone assay. Animals were killed by decapitation. Trunk blood was collected and allowed to clot at room temperature for $15 \mathrm{~min}$. Sera were stored at $-10^{\circ} \mathrm{C}$. Corticosterone concentrations were determined by a competitive protein-binding assay as previously described (19) with four modifications. The amount of $\left[{ }^{3} \mathrm{H}\right]$ corticosterone added to the $\mathrm{CBG}$ solution was doubled, the incubation time was extended to $1 \mathrm{~h}$, the $\mathrm{pH}$ of the sodium phosphate buffer was changed from 7.2 to 7.9 , and the concentration of the dextran solution used to make dextran-coated charcoal was increased from 3.75 to $10 \mathrm{mg} / \mathrm{ml}$. These changes greatly improved the stability of binding.

Statistics. Individual differences between means were evaluated by a two-tailed Student's $t$ test for unpaired values. Trends with age in studies 1,2 , and 3 were evaluated by analysis of variance.

\section{RESULTS}

Study 1. Effect of age on response of serum corticosterone to ACTH administration. Figure 1 shows the serum corticosterone response of euthyroid pups to a saturating dose of ACTH at postnatal ages 10,13, and 16 days. A 2-way analysis of variance indicated that both age and treatment significantly affected serum concentrations of corticosterone [age, $\mathrm{F}(2,18)=66.1, p<0.001$; treatment, $\mathrm{F}(2,18)=71.5, p<0.001]$. There was also significant 2-way interaction between age and treatment $[\mathrm{F}(4,18)=10.2, p$ $<0.001]$. Posthoc $t$ tests showed that at all ages examined, ACTH administration produced a significant increase in serum corticosterone over that obtained by vehicle administration $(p<0.02$ in all cases). Comparison of the response of the uninjected group and the response of the vehicle-injected group shows a significant difference at 16 days $(p<0.01)$, illustrating the effect of injection stress on corticosterone levels at this age. For each group, serum corticosterone concentrations showed a progressive increase with age of the pups, indicating that basal, stress-induced and ACTHinduced levels of corticosterone are age dependent.

Study 2. Effect of thyroid status on response of serum corticosterone to $A C T H$. As previous studies have shown that hyperthyroidism induces a precocious elevation of basal concentrations of serum corticosterone (8-11), we predicted that hyperthyroidism would produce a precocious increase in maximal response of serum corticosterone to ACTH. The data shown in Figure 2 bear out the prediction. A 2-way analysis of variance showed a significant effect of treatment as well as age on concentrations of serum corticosterone elicited by ACTH [treatment, $\mathrm{F}(2,18)=$ $262, p<0.001$; age, $\mathrm{F}(2,18)=141, p<0.001]$. There was significant 2-way interaction between treatment and age $[\mathrm{F}(4,18)$ $=30.9, p<0.001]$. Posthoc $t$ tests showed that even at 10 days of age, there was a highly significant difference between the response of hyperthyroid and control pups to maximal stimulation by ACTH $(p<0.001)$. Moreover, the concentration of serum corticosterone in the 10-day-old hyperthyroid pups was 


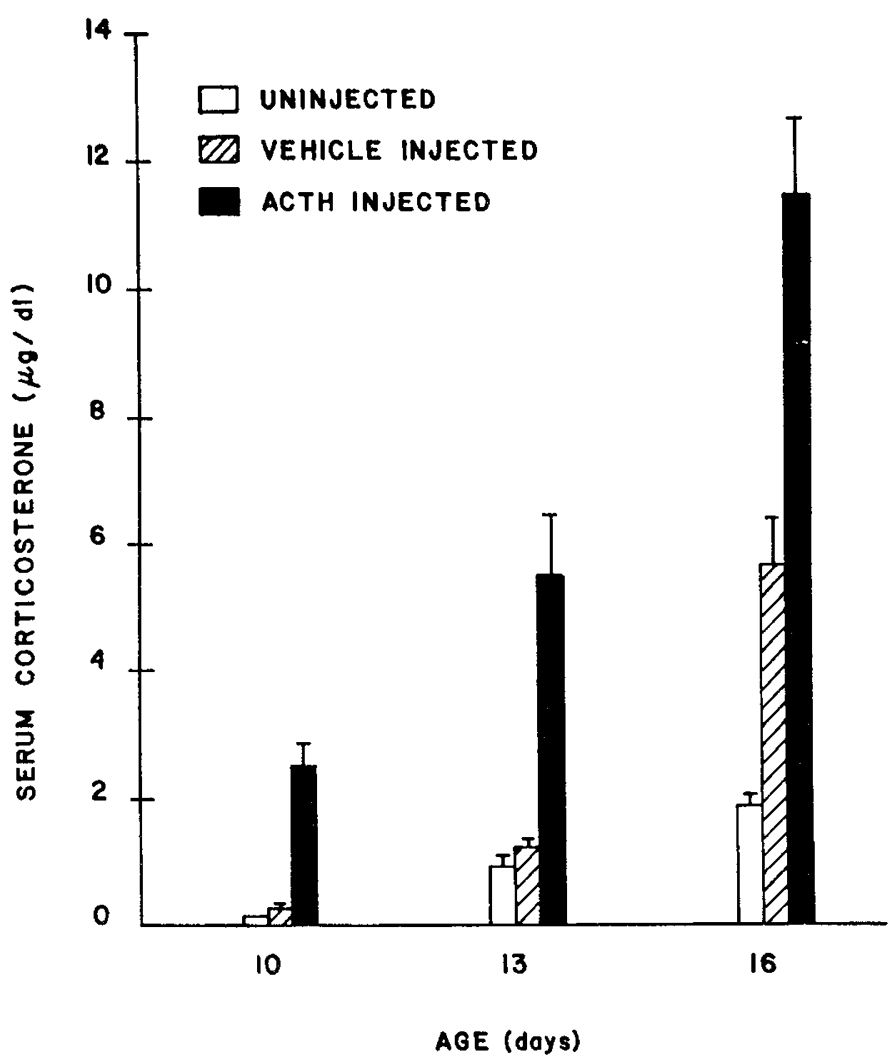

Fig. 1. Response of euthyroid rat pups to ACTH. At each age shown, the serum corticosterone in pups receiving either vehicle or ACTH (60 $\mathrm{mU} / \mathrm{g} \mathrm{BW}$ ) injections is compared with that in uninjected pups. Serum corticosterone values are given as means $\pm \mathrm{SE}(n=3)$. Lack of error bar indicates that the SE is smaller than the symbol.

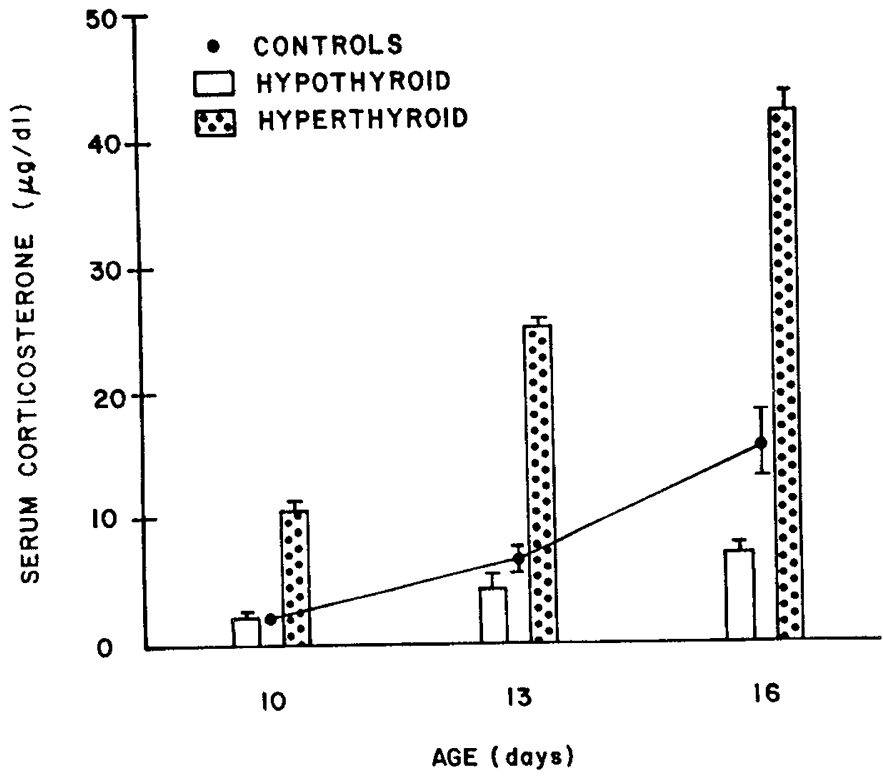

Fig. 2. Response of control, hyperthyroid, and hypothyroid rat pups to ACTH. All pups received ACTH $(60 \mathrm{mU} / \mathrm{g} \mathrm{BW}) 32 \mathrm{~min}$ before sacrifice. Serum corticosterone values are given as means $\pm \mathrm{SE}(n=3)$. Lack of error bar indicates that the SE is smaller than the symbol.

higher than that in control pups at 13 days of age, indicating that the developmental increase in the response to ACTH was advanced by more than 3 days. The effect of hyperthyroidism was to cause a sustained increase in the response to ACTH. This is indicated by the fact that at both 13 and 16 days of age, serum corticosterone values were significantly higher in the hyperthyroid animals than in their age-matched controls $(p<0.001$ in both cases).

In contrast to the precocious increase of the serum corticosterone reponse to ACTH in the hyperthyroid pups, the hypothyroid pups showed a delayed increase. At 16 days of age, the serum concentration of corticosterone elicited by ACTH in hypothyroid pups (Fig. 2) was significantly lower than that elicited in 16-day control pups $(p<0.05)$. Comparison with the control curve shows that 16-day hypothyroid pups were approximately equal to 13-day control pups, suggesting that the hypothyroid state delayed the rise in the response of serum corticosterone to ACTH by approximately 3 days.

Study 3. Effect of thyroid status on response of serum corticosterone to dibutyryl cAMP administration. In adult rats the stimulatory effect of ACTH on adrenal corticosterone production appears to be mediated by cAMP $(14,20)$. Thus, the effects of hyper- and hypothyroidism that were demonstrated in study 2 could be due to either: a) changes in the ability of ACTH to elevate adrenal cAMP; $b$ ) changes in adrenal responsiveness to cAMP; or c) action at a site other than the adrenal. To investigate the first two possibilities hyperthyroid, hypothyroid, and control pups were given a saturating dose of dibutyryl cAMP. The results are shown in Figure 3. A 2-way analysis of variance indicated that the response of serum corticosterone to dibutyryl cAMP was significantly affected by age and treatment [age, $\mathrm{F}(2,35)=38.0, p<0.001$; treatment, $\mathrm{F}(2,35)=59.1, p<$ $0.001]$. Furthermore, there was significant 2-way interaction between age and treatment $[\mathrm{F}(4,35)=7.15, p<0.001]$. Post hoc $t$ tests showed that at each age, hyperthyroid pups exhibited significantly higher concentrations of serum corticosterone in response to dibutyryl cAMP than did the respective control pups, with $p<0.005$ in all cases. At 13 and 16 days of age, the serum corticosterone response to dibutyryl cAMP in hypothyroid pups was significantly lower than that in age-matched control pups, with $p<0.005$ and $p<0.01$, respectively. As in Figure 2, the effect of hyper- and hypothyroidism was to advance and delay the increase of the serum corticosterone response to dibutyryl cAMP (Fig. 3) by approximately 3 days. Comparison of Figures 2 and 3 also shows that the absolute magnitude of serum corti-

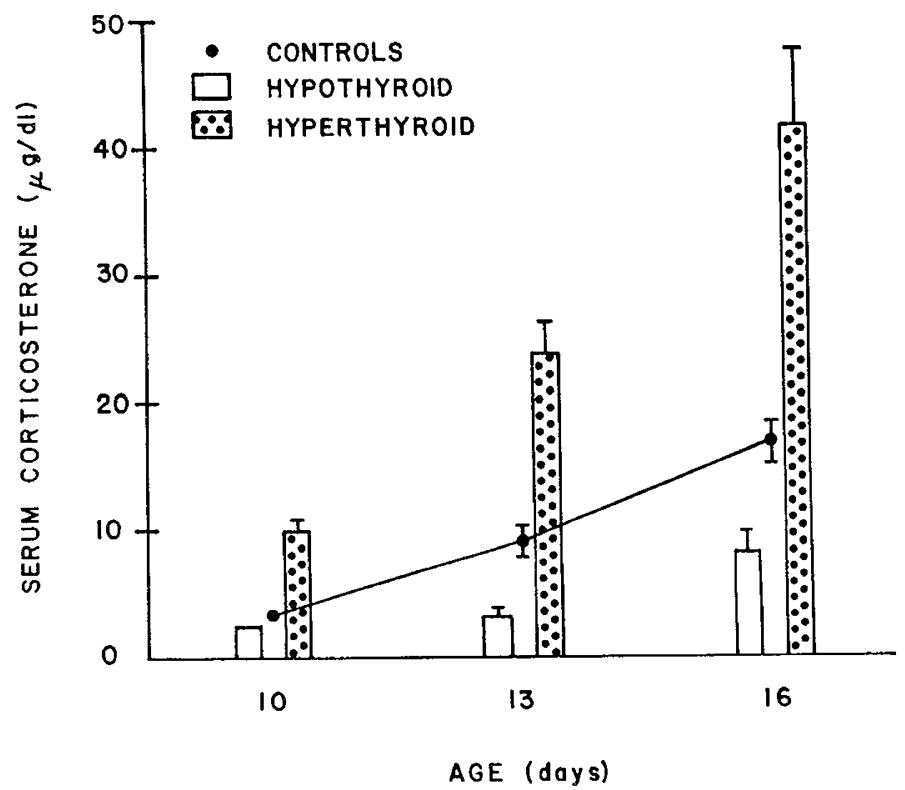

Fig. 3. Response of control, hyperthyroid, and hypothyroid rat pups to dibutyryl cAMP. All pups received dibutyryl cAMP $32 \mathrm{~min}$ before sacrifice. Serum corticosterone values are given as means $\pm \operatorname{SE}(n=5$, except for hypothyroid pups on day 10 where $n=4$ ). Lack of error bar indicates that the SE is smaller than the symbol. 
costerone values obtained in control, hyperthyroid, and hypothyroid pups was very similar, indicating that the animals responded almost identically to maximal stimulation by ACTH (Fig. 2) as to maximal stimulation by dibutyryl cAMP (Fig. 3).

Study 4. In vitro production of corticosterone by adrenals from pups aged 10 and 16 days. In order to determine whether the effects of age on the serum corticosterone response to ACTH shown in Figure 1 reflect changes at the level of the adrenal itself, we measured both basal and ACTH-stimulated production of corticosterone by adrenal halves in vitro. The results are given in Table 1. When the incubation medium was Krebs-Ringer bicarbonate $(A)$, ACTH enhanced corticosterone production at both 10 and 16 days. However, in contrast to the situation in vivo (Fig. 1), the results in Table $1(A)$ show that there was no significant increase in corticosterone production by isolated adrenal tissue from 16-day-old rats as compared with 10-day-old rats, either under basal conditions $(p>0.5)$ or under ACTHstimulated conditions $(p>0.7)$.

To investigate the possibility that a circulating factor is required for adrenal tissue to demonstrate increasing production of corticosterone with increasing age, we repeated the in vitro study using homologous serum as the incubation medium. The results are shown in $B$ of Table 1 . Under these conditions there was no significant effect of added ACTH at either age. Corticosterone production in control incubations $(B)$ was very similar to that in the ACTH-stimulated condition of the Krebs-Ringer incubations $(A)$, suggesting that at both 10 and 16 days of age, serum contains sufficient ACTH to maximally stimulate the adrenal tissue. $B$ of Table 1 shows that even in the presence of serum there is no significant increase in corticosterone production with increasing age $(p>0.98$ and $p>0.5$ for basal and ACTH incubations, respectively). The high mean in the day 16 incubations in the presence of ACTH is entirely due to one aberrently high value. Omission of that value gives $1.32 \pm 0.15$ $(n=3)$ and results in $p>0.7$ compared with the day 10 value.

Study 5. Effect of thyroid status on serum corticosterone concentration resulting from exogenous corticosterone. Taken together, the data given above point strongly to the possibility that the effects of both age and thyroid status on the concentration of circulating corticosterone do not reflect changes in the rate of secretion of corticosterone by the adrenals. The aim of the present study was to directly investigate the hypothesis that thyroid status will influence the serum concentration of corticosterone resulting from an exogenous source of corticosterone as much as it does from endogenous corticosterone. For this purpose, hypo- and hyperthyroid rat pups were implanted with corticosterone pellets at 13 days of age and then were sacrificed at 16 days of age for collection of serum. The ratio of pellet weight $(\mathrm{mg})$ to body weight $(\mathrm{g})$ was $0.51 \pm 0.03(n=6)$ for the hyperthyroid pups and $0.58 \pm 0.01(n=6)$ for the hypothyroid pups. Although these values are not significantly different $(p>0.05)$, they suggest that, on the average, the hypothyroid animals received slightly more corticosterone than did their hyperthyroid littermates. Euthyroid animals were not included in this experiment because with PTU administered via the milk of the dam, it is impossible to have untreated littermates. Moreover, previous studies have shown the difficulty of finding an exact replacement dosage of $T_{4}$ in PTU-treated infant rats (8).

The results in Table 2 show that the serum concentrations of total corticosterone in the hyperthyroid pups were significantly higher than those in the hypothyroid pups $(p<0.02)$. The elevation of total serum corticosterone was accompanied by an increase in the concentration of CBG in the serum $(p<0.005)$. Moreover, examination of the extent to which the circulating corticosterone was protein bound (Table 2) showed that values for percentage bound were significantly higher in the hyperthyroid pups than in the hypothyroid ones $(p<0.001)$.

It is important to compare the data in Table 2 from pups having corticosterone implants with data from pups without such implants. In our previous study of the effects of thyroid status on serum corticosterone (8), we did not have values for day 16 . More recently, we have found that at this age, hyperthyroid pups have serum corticosterone concentrations of $8.8 \pm 0.4 \mu \mathrm{g} / \mathrm{dl}(n$ $=3$ ) whereas hypothyroid pups have $0.1 \pm 0.1 \mu \mathrm{g} / \mathrm{dl}(n=3)$. This difference of $8.7 \mu \mathrm{g} / \mathrm{dl}$ is very similar to that in Table $2(9.4$ $\mu \mathrm{g} / \mathrm{dl})$, suggesting that thyroid status affects serum concentrations of corticosterone from a pellet to the same extent that it affects endogenous corticosterone.

A question that needs to be addressed here is whether adrenal production of corticosterone could have contributed to the serum concentrations of corticosterone observed in Table 2. For this purpose we have repeated the experiment using adrenalectomized rat pups. The results showed that under these conditions, the circulating concentration of total corticosterone was $16.1 \pm$ $2.9 \mu \mathrm{g} / \mathrm{dl}(n=3)$ in hyperthyroid pups as compared with $7.6 \pm$ $0.6 \mu \mathrm{g} / \mathrm{dl}(n=3)$ in the hypothyroid pups. These values are significantly different $(p<0.05)$ and the magnitude of the difference $(8.5 \mu \mathrm{g} / \mathrm{dl})$ is similar to that in Table 1 .

\section{DISCUSSION}

The results of study 1 show that there is a marked effect of age on circulating concentrations of corticosterone under both basal and ACTH-stimulated conditions. Since the ACTH studies were all done $25 \mathrm{~min}$ postinjection, one question is whether the time course of the corticosterone response changes with age. Although we have not directly investigated this possibility, it seems unlikely in view of the fact that increasing responsiveness of serum corticosterone with increasing age between 7 and 21 days has also been reported for animals studied $5 \mathrm{~min}$ postinjection (4). A definitive answer would require determination of serum cor-

Table 2. Effect of thyroid status on serum corticosterone parameters in 16-day-old rats having corticosterone implants*

\begin{tabular}{lcc}
\hline \multicolumn{1}{c}{ Condition } & Hyperthyroid & Hypothyroid \\
\hline Total serum corticosterone & $14.3 \pm 2.1$ & $4.9 \pm 0.9$ \\
CBG concentration & $17.4 \pm 2.5$ & $0.41 \pm 0.03$ \\
\% bound corticosterone & $91.6 \pm 1.7$ & $12.8 \pm 1.3$ \\
\hline
\end{tabular}

* All values are given as means $\pm \mathrm{SE}, n=$ three litters. Units for total corticosterone are $\mu \mathrm{g} / \mathrm{dl}$ and units for $\mathrm{CBG}$ are $\mu \mathrm{g}$ corticosterone bound/ dl.

Table 1. In vitro production of corticosterone by adrenal halves from rats aged 10 and 16 days

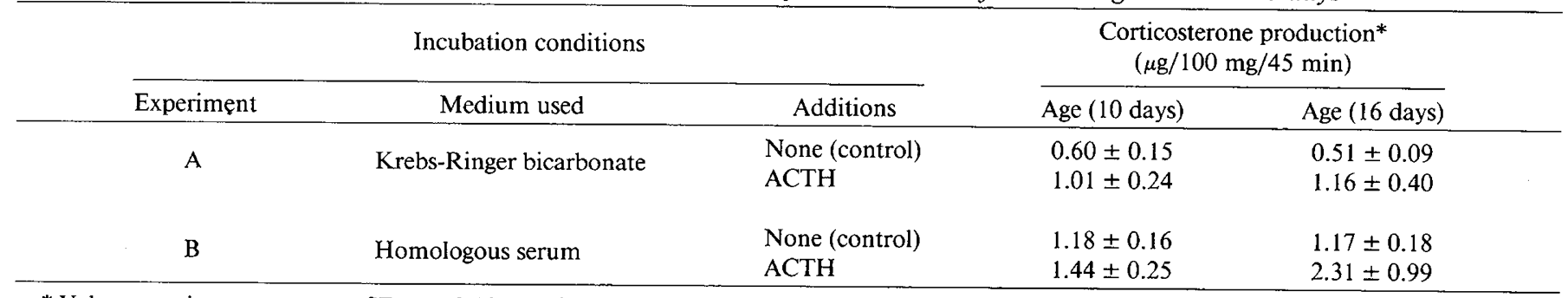

\footnotetext{
* Values are given as means $\pm \mathrm{SE}, n=8$ (litters) for experiment $\mathrm{A}$ and $n=$ four (litters) for experiment $\mathrm{B}$.
} 
ticosterone at sufficient time points to completely delineate both its rise and its fall. It is possible that peak values would be the same at all ages but that the time of the peak would be earlier in older pups than in younger pups. If this is so, there still remains the challenge to explain the mechanism of the ontogenic increase of basal concentrations of serum corticosterone in the face of constant circulating ACTH (4).

At first sight, the most logical explanation for the ontogenic increase in both basal and ACTH-stimulated concentrations of serum corticosterone would be that adrenal responsiveness to ACTH increases with age, leading to greater production of corticosterone. However, the results of study 4 show that there is no age-related increase in the in vitro production of corticosterone under either basal or ACTH-stimulated states. This was true even when conditions were optimized by incubating in homologous serum rather than in a defined medium. Other authors have also reported a lack of increase in ACTH-stimulated corticosterone production by isolated adrenal tissue from rats aged 7,14 , and 21 days (21). While negative results from in vitro studies must always be interpreted with some caution, these findings suggest that the age-related increases seen in vivo in both basal and ACTH-stimulated conditions may reflect reduced metabolic clearance of corticosterone rather than increased production.

The dramatic influence of thyroid status on basal concentrations of circulating corticosterone in the developing rat is well established (8-12). In the current investigation we have shown that thyroid status also influences ACTH-stimulated concentrations of serum corticosterone in rat pups aged 10-16 days. Specifically, the developmental increase in this parameter was advanced approximately 3 days in hyperthyroid animals and was delayed approximately 3 days in hypothyroid animals. Previous studies on the effects of $\mathrm{T}_{4}$ status on the in vivo response of serum corticosterone to ACTH yielded conflicting results (22-24) and their interpretation was complicated by the use of a fluorometric assay which is known to be inappropriate in young rodents (1, $2,7)$.

It is important to note that our findings of altered response of serum corticosterone to ACTH in hypo- and hyperthyroidism do not eliminate the possibility that ACTH production is also under thyroid control. Meserve and Leatham (22) concluded that thyroid deficiency does result in reduced release of ACTH in the infant rat. This conclusion was based on the fact that at 15 days of age, hypothyroid rats showed increased serum corticosterone in response to exogenous ACTH but not in response to ether stress (22). More recently, it has been demonstrated by immunosassay as well as by bioassay that CRF in median eminence extracts of 15-day-old rats is markedly reduced by hypothyroidism $(25,26)$. Although this supports the hypothesis that $\mathrm{ACTH}$ production is influenced by thyroid status, a firm conclusion awaits measurements of circulating concentrations of ACTH in hyper- and hypothyroid animals during dvelopment.

In the present study, the pattern of the serum corticosterone response of hyper- and hypothyroid rats to dibutyryl cAMP was virtually identical to that of saturating doses of ACTH. Assuming that ACTH action on the infant rat adrenal is mediated by cAMP, as is the case in the adult rat $(14,20)$, the similarity between our data using dibutyryl cAMP as compared with ACTH indicates that the effects of hyper- and hypothyroidism are at a site distal to cAMP formation. More detailed studies are clearly needed to fully identify the site of $\mathrm{T}_{4}$ action. It is unlikely to be a direct action on the adrenal because at 15-16 days, in vitro production of corticosterone is no greater in adrenal halves from euthyroid animals than from hypothyroid animals $(25,27)$. Moreover, our results from study 5 show that thyroid status influences the concentration of serum corticosterone resulting from an exogenous source just as much as it does endogenous corticosterone. Thus it would appear that the effect of thyroid status, just as that of age, may be due to changes in the MCR of corticosterone rather than changes in its production by the adrenal.
The question, then, is what factor is responsible for the effects of both age and $\mathrm{T}_{4}$ on both basal and ACTH-stimulated concentrations of corticosterone. The most likely candidate appears to be CBG. Previous studies have shown that circulating concentrations of this protein increase markedly in the rat between 8 and 24 days of age $(1,3)$. Moreover, this developmental increase is advanced by hyperthyroidism and is delayed by hypothyroidism (8). In both adults (28) and infants (29) the MCR of glucocorticoid hormones has been shown to be inversely proportional to the circulating concentration of $\mathrm{CBG}$, presumably reflecting a reduced rate of clearance of bound hormone. The current data (Table 2) show that the percentage of total serum corticosterone which is protein bound is markedly elevated in hyperthyroid animals. We believe this accounts for the fact that in the face of constant input of corticosterone (from a pellet), hyperthyroid pups have significantly higher concentrations of total serum corticosterone than do hypothyroid littermates.

Studies to directly determine the influence of age and thyroid status on the MCR of corticosterone in developing rats are beyond the scope of the present investigation. Given that the equation for MCR of glucocorticoids is $M C R=V 1 n 2 / t_{1 / 2}$, where $\mathrm{V}=$ virtual volume of distribution and $\mathrm{t}_{1 / 2}=$ half-life $(30)$, one can predict that decreased MCR will be associated with decreased $\mathrm{V}$ and/or increasted $t_{1 / 2}$. However, it has already been shown that the $t_{1 / 2}$ for corticosterone in the rat declines slightly between 10 and 16 days of age (31). Thus it would appear that if there is a decrease in MCR with age, it would be due to a corresponding decrease in V. Similarly, we would predict that the effects of thyroid status on corticosterone development could be accounted for by decreased $\mathrm{V}$ in hyperthyroid animals and increased $\mathrm{V}$ in hypothyroid animals. There is good precedent for this because in adult rats (32) and 6-day-old rats (29), the increased plasma concentrations of corticosterone following $T_{4}$ treatment have been ascribed primarily to decreased $\mathrm{V}$. Our further suggestion would be that decreasing values for $\mathrm{V}$ in response to both increasing age and increasing $\mathrm{T}_{4}$ are the result of the increase of CBG that occurs under these conditions $(1,3,8)$.

Acknowledgements. The authors thank Drs. C. Lau and V. Rao for their helpful comments on the manuscript.

\section{REFERENCES}

1. Henning SJ 1978 Plasma concentrations of total and free corticosterone during development in the rat. Am J Physiol 235:E451-E456

2. Schoenfeld NM, Leathem, JH, Rabii J 1980 Maturation of adrenal stress responsiveness in the rat. Neuroendocrinology 31:101-105

3. Vallette G, Delorme J, Benassayag C, Savu L, Nunez EA, Meijs-Roelofs HMA, Kramer P 1982 Developmental patterns of levels of corticosterone and of corticosterone binding in the serum of female rats: effects of ovariectomy and adrenalectomy. Acta Endocrinol 101:442-451

4. Guillet R, Michaelson SM 1978 Corticotropin responsiveness in the neonatal rat. Neuroendocrinology 27:119-125

5. Cote TE, Yasumura S 1975 Effect of ACTH and histamine stress on serum corticosterone and adrenal cyclic AMP levels in immature rats. Endocrinology 96:1044-1047

6. Hiroshige T, Sato T 1971 Changes in hypothalamic content of corticotropinreleasing activity following stress during neonatal maturation in the rat. Neuroendocrinology 7:257-270

7. Diez JA, Sze PY, Ginsburg BE 1976 Postnatal development of mouse plasma and brain corticosterone levels; new findings contingent upon the use of a competitive protein-binding assay. Endocrinology 98:1434-1442

8. D'Agostino JB, Henning SJ 1982 Role of thyroxine in coordinate control of corticosterone and CBG in postnatal development. Am J Physiol 242:E33E39

9. Malinowska KW, Chan WS, Nathanielsz PW, Hardy RN 1974 Plasma adrenocorticosteroid changes during thyroxine-induced accelerated maturation of the neonatal rat intestine. Experientia 30:61

10. Martin SM, Moberg GP. 1981 Effects of early neonatal thyroxine treatment on development of the thyroid and adrenal axes in rats. Life Sci 29:16831688

11. Poland RE, Weichsel ME Jr, Rubin RT 1979 Postnatal maturation patterns of serum corticosterone and growth hormone in rats: effect of chronic thyroxine administration. Horm Metab Res 11:222-227

12. Yeh KY, Moog F 1977 Influence of the thyroid and adrenal glands on the growth of the intestine of the suckling rat, and on the development of intestinal alkaline phosphatase and disaccharidase activities. J Exp Zool 200:337-348 
13. Blake HH, Henning SJ. 1985 Effect of propylthiouracil dose on serum thyroxine, growth, and weaning in young rats. Am J Physiol 248:R524-R530

14. Grahame-Smith DG, Butcher RW, Ney RL, Sutherland EW 1967 Adenosine $3^{\prime}, 5^{\prime}$-monophosphate as the intracellular mediator of the action of adrenocorticotropic hormone on the adrenal cortex. J Biol Chem 242:5535-5544

15. Holmes SD, Neto FR, Field JB 1980 Effect of in vivo treatment with adrenocorticotropin and hypophysectomy on adrenal adenosine $3^{\prime}, 5^{\prime}$-monophosphate and corticosterone responsiveness to adrenocorticotropin stimulation in vitro. Endocrinology 107:432-437

16. Koroscil TM, Gallant S 1980 On the mechanism of action of adrenocorticotropic hormone. J Biol Chem 255:6276-6283

17. Meyer JS, Micco DJ, Stephenson BS, Krey LC, McEwen BS 1979 Subcutaneous implantation method for chronic glucocorticoid replacement therapy. Physiol Behav 22:867-870

18. Martin CE, Cake MH, Hartmann PE, Cook IF 1977 Relationship between foetal corticosteroids, maternal progesterone, and parturition in the rat. Acta Endocrinol 84:167-176

19. Henning, SJ 1980 A sensitive and convenient method for measurement of corticosterone in rat serum. Steroids 35:673-683

20. Koroscil TM, Gallant S 1981 The phosphorylation of adrenal proteins in response to adrenocorticotropic hormone. J Biol Chem 256:6700-6707

21. Guillet R, Saffran M, Michaelson SM 1980 Pituitary-adrenal response in neonatal rats. Endocrinology 106:991-994

22. Meserve LA, Leathem JH. 1973 Hypothyroidism and the maturation of the hypothalamo-hypophyseal-adrenal axis. Dev Psychobiol 6:123-129

23. Meserve LA, Leathem JH 1974 Neonatal hyperthyroidism and maturation of the rat hypothalamo-hypophyseal-adrenal axis. Proc Soc Exp Biol Med $147: 510-512$

24. Meserve LA, Leathem JH 1981 Development of hypothalamic-pituitary-adrenal response to stress in rats made hypothyroid by exposure to thiouracil from conception. J Endocrinol 90:403-409

25. Meserve LA, Pearlmutter AF 1983 Perinatal thiouracil exposure depresses corticotropin-releasing factor activity in 15 day old rats. Horm Metabol Res 15:488-490

26. Meserve LA 1984 Depressed hypothalamic CRF immunoreactivity in 15 day old thiouracil-treated rats. Horm Metabol Res 16:674-675

27. Kolena J, Macho L, Palkovic M, Poor J 1968 Steroidogenic enzyme systems in the rat adrenal glands during postnatal development. Gen Comp Endocrinol 10:247-252

28. Siiteri PK, Murai JT, Hammond GL, Nisker JA, Raymoure WJ, Kuhn RW 1982 The serum transport of steroid hormones. Rec Prog Horm Res 38:457510

29. Koch B, Lutz B, Schmitt G, Mialhe C 1970 Influence of transcortin on degradation and tissue uptake of corticosterone in the infant rat. Horm Metab Res 2:292-297

30. Tait JF, Burstein S 1964 In vivo studies of steroid dynamics in man. In: Pincus G, Thimann KV (eds) The Hormones. Academic Press, New York, pp 441557

31. Schapiro S, Percin CJ, Kotichas FJ 1971 Half-life of plasma corticosterone during development. Endocrinology 89:284-286

32. Steinetz BG, Beach VL 1963 Some influences of thyroid on the pituitaryadrenal axis. Endocrinology $72: 45-58$ 